\title{
Índice de preços hedônicos para apartamentos: uma aplicação a dados fiscais de Belo Horizonte, 1995-2012 *
}

\author{
Luiz Andrés Ribeiro Paixão ${ }^{* * * * * *}$ \\ Viviane Luporini ${ }^{* * * *}$
}

\begin{abstract}
Resumo
Esse trabalho tem como objetivo discutir as metodologias hedônicas mais difundidas para a construção de índices de preços e aplicá-las para uma base de dados fiscais do município de Belo Horizonte, entre 1995 e 2012. Os resultados para os índices de preços pelos diversos métodos hedônicos estimados registraram uma intensa valorização imobiliária em Belo Horizonte, a partir de 2005, impulsionada pelo aumento na oferta de crédito imobiliário, que se tornou possível após as melhorias no instituo de alienação fiduciária, em 2004. Além disso, a redução nas taxas de juros, o crescimento econômico observado no período e o aumento da renda real das famílias também contribuíram para o bom desempenho dos preços dos imóveis. Mesmo após a crise mundial de 2008/2009, a valorização imobiliária continuou intensa até meados de 2012, possivelmente devido às políticas anticíclicas implementadas pelo Governo Federal. Esses resultados demonstram que a utilização da metodologia hedônica em uma base de dados fiscais constitui uma estratégia promissora para a implementação de um futuro índice de preços oficial para imóveis no Brasil.
\end{abstract}

Palavras-chave: Mercado imobiliário, Preços hedônicos, Índice de Preços, Belo Horizonte.

\section{Abstract \\ Hedonic price index for apartments: an analysis of data from Belo Horizonte (Brazil), from 1995 to 2012}

This paper presents the more commonly used methods of hedonic estimation and applies them to a fiscal data base from Belo Horizonte, Brazil, 1995-2012. The results of the price indexes from the various estimations suggest a pronounced real estate appreciation from 2005 to 2012. Increasing real estate financing (after the statutory lien legislation of 2004), falling interest rates and growth in real family income contributed to the positive performance of the real estate market in the period. Results also indicate that real estate prices continued to increase despite the world financial crisis of 2008/2009 possibly due to countercyclical policies implemented by the Brazilian Government. These results help to shed light on the potential use of hedonic price models and a fiscal database to construct an official housing price index for Brazil in the future.

Keywords: Real estate market, Hedonic price model, Prices indices. Belo Horizonte.

JEL R21, R31, C1.

\footnotetext{
${ }^{*}$ Artigo recebido em 7 de julho de 2017 e aprovado em 19 de fevereiro de 2020.

** Analista do Instituto Brasileiro de Geografia e Estatística (IBGE), Rio de Janeiro, RJ, Brasil. E-mail: luiz.paixao@ibge.gov.br. ORCID: https://orcid.org/0000-0002-6378-9518.

*** Professor Colaborador da Escola Nacional de Ciências Estatísticas (ENCE), Rio de Janeiro, RJ, Brasil.

**** Professora associada do Instituto de Economia da Universidade Federal do Rio de Janeiro (IE/UFRJ), Rio de Janeiro, RJ, Brasil. E-mail: viviane.luporini@ie.ufrj.br. ORCID: https://orcid.org/0000-0001-9629-5058.
} 


\section{Introdução}

Índice de preços é um dos indicadores econômicos popularmente mais utilizados. Porém, construir um índice de preços é tarefa complexa. Como pontua Hill (2013), economistas consagrados - como Jevons, Fisher, Marshall, Keynes e Samuelson - debruçaram-se sobre o assunto. A construção de índice de preços para imóveis apresenta algumas especificidades que tornam essa tarefa ainda mais complexa. Primeiramente, o imóvel é um bem composto por diversas características que torna cada unidade particularmente distinta da outra. Nesse ponto, de acordo com Hill (2013), o imóvel é um caso extremo de bens compostos, uma vez que para a maioria dos bens duráveis as características se alteram por modelos (como no caso de automóveis, geladeiras, microcomputadores, etc.). Além disso, parte do preço dos imóveis é definido pela sua localização, sendo assim, o componente espacial deve ser levado em conta na construção dos índices. Por fim, as vendas de imóveis se dão de forma inconstante no tempo, não sendo possível construir uma cesta de bens para extrair índices periódicos.

Em artigo sintetizando os trabalhados apresentados no workshop realizado pela Organização para a Cooperação e Desenvolvimento Econômico (OCDE) sobre índice de preços para imóveis, em 2006, Diewert (2009) concluiu que o modelo de preços hedônicos é o mais adequado para gerar índices de preços imobiliários ${ }^{1}$. Muitos índices são construídos utilizando a valorização mediana, a partir de uma combinação de características (em geral uma combinação de localização e tamanho). Essa metodologia é conhecida como modelos estratificados e é limitada, pois a possibilidade de se inserir uma gama de características é pequena (Diewert, 2009). No Brasil, essa metodologia é aplicada na construção dos índices Fipe-Zap, IVG-R do Banco Central, IPEAD e a publicada pelo caderno "Morar Bem" do jornal O Globo.

Outro método muito utilizado é o modelo das vendas repetidas (MVR) concebido por Bailey, Muth e Nourse (1963) e que consiste em estimar uma regressão para uma amostra reduzida a imóveis que foram vendidos ao menos duas vezes em um determinado período de tempo. Teoricamente a questão das características é resolvida ao se limitar a amostra às revendas. Porém, a principal crítica a esse método é que ao reduzir a amostra a apenas revendas, pode-se gerar um viés de seleção, dado que determinados tipos de imóveis tendem a apresentar uma rotação de estoque maior. Adicionalmente, algumas características dos imóveis podem mudar ao longo do tempo devido à depreciação, a reformas ou a mudanças ambientais na localização. ${ }^{2}$ Por todas essas razões, Diewert (2009) prefere a utilização dos modelos hedônicos.

O modelo de preços hedônicos (MPH) consiste em uma regressão (ou um conjunto de regressões) das características do bem no seu preço. Dessa forma, o MPH estima o preço

(1) Workshop on Real Estate Price Indexes, realizado em 2006.

(2) Apesar de suas limitações, o MVR é muito utilizado por instituições financeiras. O exemplo mais famoso de índice de preços imobiliários calculado pelo método de vendas repetidas é o Índice Case/Shiller. 
implícito de cada característica, ou seja, o peso de cada característica na formação do preço do bem.

As primeiras aplicações do MPH foram feitas por Waugh (1928) (estimando índice de preços de vegetais), e Court (1939) (estimando índice de preços para automóveis). Griliches $(1961 ; 1971)$ buscou sistematizar o MPH como ferramenta para estimar índice de preços para bens duráveis. De acordo com Diewert (2009), o MPH é o modelo mais completo para estimar índices de preços imobiliários, pois diferentemente dos modelos de vendas repetidas, não desperdiça informação amostral e, ao contrário dos modelos estratificados, permite inserir um grande número de características de imóveis. Além disso, o MPH permite inserir os efeitos da depreciação, reformas e mudanças na vizinhança no cálculo do índice, o que não é possível nos outros dois modelos.

A aplicação do MPH na construção de índice de preços por órgãos de estatísticas oficiais tem se difundido ao longo do tempo, principalmente nos países europeus após recomendação da OCDE. Nos EUA, o Census Bureau utiliza o MPH desde 1968 no cálculo do The New House Price Index. O INSEE - órgão de estatística oficial da França - calcula o índice Conseil Supérieur du Notarist desde 1999, cuja série retrocede a 1994.

$\mathrm{Na}$ academia, a estimação de índice de preços para imóveis tem sido frequente com exemplos de artigos utilizando tanto o MVR quanto o MPH. Gatzlaff e Ling (1994) estimaram índice de preços imobiliários com dados do registro administrativo para a Região Metropolitana de Miami (EUA), 1991-2001, aplicando os modelos hedônico e de vendas repetidas. Os dois modelos também foram utilizados por Hoesli, Giacotto e Favarger (1997) para estimar um índice de preços imobiliários para Genebra (Suíça), entre 1968 e 1993. Maurer, Pitzer e Sebastian (2004) utilizaram o modelo de preços hedônicos para estimar a valorização imobiliária em Paris (França), 1990-1999, vis-à-vis o retorno de ativos financeiros como títulos e ações. Pavese (2007) estimou índice de preços para Turim (Itália), 2003-2007, pela modelagem hedônica. Hill, Melser e Syed (2009) utilizaram essa mesma metodologia, MPH, para avaliar o comportamento do mercado imobiliário da cidade de Sydney (Austrália) entre 2001 e 2006.

No Brasil, a literatura empírica devotada à estimação de índice de preços imobiliários através de modelagem hedônica tem se tornado mais extensa e vem avançado no que diz respeito tanto aos métodos empregados quanto em relação à base de dados. Algumas contribuições utilizaram o método mais simples e intuitivo, que consiste em estimar uma única regressão hedônica para todo o painel, utilizando uma dummy de tempo para cada período método conhecido na literatura como time-dummy (TD). Outras contribuições avançaram no quesito metodológico e estimaram os índices de preços imobiliários a partir de um conjunto de regressões hedônicas, procedimento tido como mais robusto uma vez que permite que os parâmetros estimados variem no tempo. Em trabalho pioneiro, González (1997) utilizou a metodologia TD para estimar índice de preços para os aluguéis em Porto Alegre, entre 1993 e 1996, a partir de uma base de dados proveniente de imobiliárias. O objetivo do autor era 
analisar o comportamento dos aluguéis na época da implantação do Plano Real - que tem como marco o lançamento da moeda Cruzeiro Real em 1/07/1994. González (1997) concluiu que entre janeiro de 1993 e setembro de 1994 os preços dos aluguéis em Porto Alegre não acompanharam a inflação. No período que vai de outubro de 1994 até julho de 1996, no entanto, houve valorização real do preço dos aluguéis na capital gaúcha e, posteriormente (até dezembro de 1996 quando termina o painel do estudo), o valor se estabilizou.

Paixão (2015) utilizou a base de dados do ITBI para, através da metodologia TD, estimar índices de preços imobiliários para Belo Horizonte, entre 1996 e 2003. O objetivo do autor era, através de uma base de dados abrangente, discutir a possibilidade de implantação de um índice de preços para imóveis no Brasil e interpretar os indicadores estimados a luz da conjuntura macroeconômica do período. Coincidentemente, as análises de Paixão (2015) e González (1997) se complementam quanto ao período analisado. Em Belo Horizonte, entre 1996 e 1998, houve valorização real do preço dos imóveis. Tendência que foi revertida no período 1999 e 2003, no qual a valorização imobiliária não acompanhou a inflação.

Bianconi e Yoshino (2013) estimaram índices de preços para imóveis no município de São Paulo, entre 2001 e 2008, a partir de uma base de dados de lançamentos imobiliários. Os autores partiram da premissa de que a variação do preço dos imóveis incorpora fatores cíclicos do próprio mercado imobiliário e fatores mais gerais associados ao ciclo de negócios da economia. Com esse propósito estimaram índices de preços utilizando tanto o método TD simples, quanto um conjunto de regressões hedônicas. Para esse último método, as regressões foram utilizadas para imputar o valor de um imóvel médio fixo (média do período base) em diversos pontos do tempo - técnica conhecida como método das características. Os autores concluem que para sua base de dados, o método TD exibiu um comportamento superior ao método das características. Em parte, esse resultado pode ser explicado pela limitação da base de dados. Ao utilizarem uma base de dados de lançamentos imobiliários, o baixo número de observações comprometeu os resultados do método das características. Por outro lado, o método TD, por ser baseado em uma única regressão, acaba se adequando melhor a amostras diminutas. A partir dos índices gerados pelo método TD, os autores avaliaram que o volume de crédito na economia, a taxa de câmbio e o comportamento do mercado imobiliário americano são fatores que influenciam na dinâmica dos preços imobiliários brasileiros.

Rozenbaum (2009) avançou na discussão metodológica ao construir um índice de preços para o mercado imobiliário do município do Rio de Janeiro, entre 1995 e 2007, a partir de um conjunto de regressões hedônicas time-dummy, tendo como base de dados o ITBI. Segundo o autor, o ciclo da construção civil no Brasil dura três anos e, por isso, a magnitude dos parâmetros da regressão hedônica pode ser considerada estável nesse intervalo de tempo. Por isso, Rozenbaum (2009) estimou uma regressão hedônica TD a cada três anos para calcular o índice de preços para apartamentos no Rio de Janeiro. O objetivo do seu trabalho era mostrar a possibilidade de se calcular índices de preços de imóveis municipais no Brasil a partir da base de dados do ITBI. O autor concluiu que a aplicação da modelagem hedônica à base do ITBI para estimar índice de preços para imóveis no Brasil é promissora. Analisando o índice 
estimado, Rozenbaum (2009) constatou que a variação do preço dos imóveis no Rio de Janeiro ficou muito próxima da inflação (IPCA) e muito abaixo da taxa de juros básica da economia (SELIC), durante o período.

Rêgo (2009) utilizou um conjunto de regressões hedônicas - método das características - para estimar índice de preços para o Brasil e Regiões Metropolitanas a partir da base de dados da Pesquisa Nacional por Amostra de Domicílios (PNAD) do IBGE, entre 1995 e 2007. Para calcular os índices utilizou como vetor de características a serem imputadas o imóvel médio de 1995, definido como ano base. Aplicando esse vetor de características médias aos parâmetros das regressões anuais, o autor estimou o preço do imóvel médio ao longo do tempo. Ao estimar regressões anuais e utilizar uma base de dados com grande número de observações, Rêgo (2009) contornou os problemas encontrados por Bianconi e Yoshino (2013) ao utilizarem o método das características. O objetivo do trabalho era demonstrar a importância de índices de preços de aluguéis se basearem em alguma metodologia que controle o efeito composição das características na variação do preço do imóvel. Comparando os resultados do índice estimado em seu trabalho ao IPCA-aluguel, Rêgo (2009) constatou que esse último exibiu valores maiores em todo o período. Ou seja, para o período em questão, o IPCA-aluguel superestimou a variação de preços dos aluguéis, fato que o autor atribui à ausência de controle na variação qualitativas dos imóveis observados. Comparando o comportamento do índice de aluguel estimado em seu trabalho com a inflação (IPCA), Rêgo (2009) constata que até 1998 a variação do aluguel esteve acima da inflação, tendência que se inverteu a partir de 1999.

Tendo em vista a discussão acima, o presente trabalho visa contribuir para a literatura nacional nos seguintes pontos. Do ponto de vista teórico, busca incorporar na literatura nacional a discussão da taxonomia dos diversos métodos de estimação de índices de preços hedônicos para o mercado imobiliário proposta por Hill (2013). Em uma perspectiva empírica, o artigo estima os índices de preços nas diferentes metodologias hedônicas, permitindo uma análise comparativa dos diversos métodos. A base de dados escolhida foi a do ITBI na medida em que essa é considerada a mais abrangente para estudos do mercado imobiliário brasileiro. Acreditamos que a aplicação das diversas metodologias hedônicas propostas por Hill (2013) aos dados do ITBI será uma importante contribuição ao debate sobre a construção de um índice de preços imobiliários oficial para o Brasil (Nadalin; Furtado, 2011; Santos; Salazar, 2011). Posteriormente, os índices calculados são interpretados à luz da conjuntura econômica nacional e comparados com os resultados do IVG-R.

O trabalho encontra-se estruturado da seguinte maneira: na seção 1, são apresentadas as várias metodologias existentes para se mensurar índice de preços imobiliários. Na segunda seção, apresentamos os diversos métodos hedônicos de estimação de índice de preços pelo modelo de preços hedônicos, seguindo a tipologia estabelecida por Triplett (2004) e Hill (2013). A seção 3 descreve os resultados dos índices estimados pelos diferentes métodos hedônicos, aplicados à base de imóveis de Belo Horizonte. Posteriormente, comparamos os métodos entre si, e os índices gerados por outras metodologias. Por fim, a conclusão sintetiza 
os principais resultados do trabalho, propõe trabalhos futuros e ressalta a importância da estimação de índice de preços de imóveis para a proposição de políticas.

\section{Metodologias para mensurar índice de preços para imóveis}

O imóvel é um bem diferenciado, sendo que seu preço é determinado pelo conjunto de características que o compõe. Porém, o bem imóvel é um tipo especial de bem diferenciado, pois cada unidade imobiliária se difere da outra (Hill, 2013). Por exemplo, mesmo dois apartamentos localizados no mesmo andar do mesmo prédio se diferenciam pela posição que ocupam. Portanto, até mesmo as metodologias existentes para mensurar índice de preços para bens duráveis têm que se adaptar a essa característica peculiar do bem imóvel. Além disso, a venda de cada unidade do bem imóvel no tempo se dá de forma infrequente (Hill, 2013), o que torna impossível construir uma cesta de unidades imobiliárias e acompanhar o comportamento dos preços ao longo do tempo. ${ }^{3}$

O preço do bem imóvel pode ser representado pela seguinte função:

$$
p=f(z)
$$

Sendo $p$ o preço do imóvel e $z$ o conjunto das n características dos imóveis, $z=\left(z_{1}+z_{2}+\ldots+z_{n}\right)$.

A média (ou a mediana) simples não é um bom indicador para a variação temporal do preço do imóvel, pois não considera as diferenças nas características $(z)$ dos imóveis entre um período e outro.

Supondo dois períodos de tempo, $s$ e $t$, temos que a variação média de preço observada é dada por $\Delta \overline{p_{t s}}=\overline{p_{t}} / \bar{p}_{s} \cdot{ }^{4}$ Porém, essa variação média não considera a diferença temporal na média das características $\left(\Delta \bar{z}_{t s}=\bar{z}_{t} / \bar{z}_{s}\right)$. A variação "pura" de preços $\left(\Delta \Pi_{t s}\right)$, utilizando a terminologia cunhada por Griliches (1971), é dada pela variação dos preços observada descontando-se o efeito da variação das características em cada período (efeito composição). Isto é:

$$
\Delta \bar{\Pi}_{t s}=\Delta \bar{p}_{t s}-\Delta \bar{z}_{t s}
$$

Nota-se que só na hipótese de as características dos imóveis transacionados não mudarem $\left(\Delta \bar{z}_{t s}=0\right)$ a média ou a mediana seriam medidas adequadas da variação "pura" do preço dos imóveis no tempo. Como visto, no caso específico do bem imóvel, essa hipótese é

(3) Nessa análise se abstrai da questão relativa à depreciação e obras de melhoria e renovação que tornam ainda mais complexa a análise temporal do preço dos imóveis. O mesmo imóvel em tempos distintos tem características distintas dado o efeito da depreciação. Caso tenha passado por reformas e melhorias, a mesma unidade passa a ter características distintas no tempo.

(4) Análise análoga vale para a mediana dos preços e características. 
extremamente restritiva. Portanto, para mensurar a variação do preço do bem imóvel no tempo é necessária alguma metodologia que leve em conta o efeito composição $\left(\Delta \bar{z}_{t s}\right)$.

No modelo estratificado o $\Delta z_{t s}$ é mensurado a partir da combinação de uma ou mais características do imóvel. Porém, esse método permite adicionar apenas um número reduzido de características. No MVR, o controle da variação nas categorias se dá limitando o âmbito da amostra a revendas. Esse método tende a maximizar o número de elementos de $z$, ao custo de limitar o tamanho da amostra. Além disso, o MVR não esgota totalmente o conjunto de características dos imóveis, pois algumas delas estão relacionadas com o tempo, como nos casos da depreciação, das reformas e das características ambientais da localização. Nos modelos hedônicos, tidos como os mais completos para índice de preços imobiliários (Diewert, 2009), o controle pelas características se dá por regressão (ou um conjunto de regressões) multivariada, permitindo que se insira um grande número de características dos imóveis. Em relação ao MVR, o modelo de preços hedônicos (MPH) não desperdiça informação, utilizando todo o universo de transações imobiliárias e não apenas um subconjunto dessas. Além disso, o MPH permite, havendo informação disponível, incorporar os efeitos da depreciação, reformas e ou mudanças nas características da vizinhança dos imóveis ao longo do tempo. Como qualquer modelo regressão, no entanto, o modelo de preços hedônicos pode apresentar o chamado viés da variável omitida, uma vez que não é possível obter informação sobre todas as características dos imóveis transacionados (Hill, 2013).

\subsection{Modelo de Preços Hedônicos (MPH)}

O MPH associa o preço do bem ao seu conjunto de atributos (características). A função hedônica de preços é justamente uma relação entre o preço do bem e seu conjunto de características, como na expressão (1) apresentada anteriormente. A contribuição de cada característica ao preço do bem é dada pela primeira derivada da função hedônica de preços e é conhecida na literatura sobre preços hedônicos como "preço-sombra" ou "preço implícito".

Embora o primeiro trabalho utilizando a metodologia date de 1928 (Waugh, 1928) foi com os trabalhos de Griliches $(1958,1961)$ que a técnica se disseminou na literatura econômica e na literatura de números índices. Rosen (1974) publicou um artigo seminal microfundamentando a função hedônica de preços para bens compostos, a partir da premissa de que existe um mercado específico e competitivo para cada característica do bem, com consumidores e produtores. O preço-sombra de cada característica é aquele em que o consumidor e o vendedor maximizam suas respectivas funções objetivo e, consequentemente, os pontos da função hedônica representam pontos de equilíbrio no mercado de cada característica.

\section{Métodos hedônicos para mensurar índices de preços para imóveis}

A implementação de métodos de preços hedônicos para mensurar índices de preços pode ser feita de várias formas. Court (1939) utilizou um modelo com dummy para cada período 
de tempo, para construir índice de preços para automóveis. Griliches (1961) propôs, a partir do trabalho de Court, a construção de índice de preços hedônicos partindo de um conjunto de regressões cross-sections. Triplett (2004) empreendeu um esforço em sistematizar os diversos métodos hedônicos criando uma taxonomia. Hill (2013) adaptou essa taxonomia para o caso da estimação de índice de preços imobiliários. Ao todo, são quatro métodos que podem ser divididos em duas classes: métodos para dados em painel e métodos para estimação crosssection.

\subsection{Métodos hedônicos para dados em painel}

\subsubsection{O método hedônico "time-dummy"}

De acordo com Hill (2013), o método hedônico "time-dummy" (TD) pode ser considerado o método original por ser o mais intuitivo, tendo sido utilizado na análise pioneira de Court (1939). O método "time-dummy" consiste em estimar uma única regressão em painel do tipo pooled (dados empilhados) com efeitos fixos no tempo. Triplett (2004) e Hill (2013) recomendam a forma funcional semilogarítmica. A regressão TD e o índice de preço são estimados pelas expressões abaixo:

$$
\ln (p)=Z \beta+D \delta+\xi
$$

onde $\ln (p)$ é o logaritmo do preço do bem imóvel; $Z$ o conjunto de características do imóvel; $\beta$ são os parâmetros estimados pela regressão e representam o preço-sombra de cada característica; $D$ é um conjunto de variáveis do tipo dummy, que representam cada período de tempo analisado, e seus respectivos parâmetros, $\delta$; e $\xi$ é o termo de erro ou resíduo da regressão.

Em geral, o período inicial de análise é o período base. O índice de preço é calculado pela seguinte fórmula:

$$
\hat{P}_{t}=\exp \left[\hat{\delta}_{t}-\frac{1}{2} \hat{V}\left(\hat{\delta}_{t}\right)\right]
$$

onde $\hat{P}_{t}$ é o índice de preço no período $t, \hat{\delta}_{t}$ é o parâmetro estimado para a dummy de tempo em $t$ e $\hat{V}\left(\hat{\delta}_{t}\right)$ representa a variância estimada para o parâmetro $\hat{\delta}_{t}{ }^{5}$.

O método TD tem como maior vantagem o fato de ser intuitivo e de simples aplicação. Porém, o método tem implícita a hipótese de que os preços-sombra não variam no tempo. Para o método TD ser robusto é necessário que as condições de oferta e demanda sejam estáveis ao longo do tempo. No caso dos bens imóveis, é razoável supor que essas condições de oferta e demanda variem lentamente no tempo, de modo que, para períodos razoavelmente curtos, o método TD fornece uma boa aproximação da valorização imobiliária. Por esse motivo, esse

(5) Inserir o termo da variância é uma forma de minimizar o viés na estimação de variáveis do tipo dummy em modelos semilogarítmicos (Kennedy, 1980). 
método é o mais utilizado na literatura acadêmica de preços imobiliários (Hill, 2013). Uma outra crítica que se faz ao método TD é o fato da fórmula do índice não ser compatível com nenhuma fórmula conhecida na literatura de números índices (Griliches, 1971; Triplett, 2004; Hill, 2013) ${ }^{6}$. Além disso, esse método não é adequado para instituições que divulgam índice de preços periodicamente, uma vez que a adição de informação de um período subsequente gera a necessidade de se re-estimar a regressão (3) e, consequentemente, gerar novos valores para todos os índices previamente divulgados, algo não muito prático. Por fim, o método TD, por se basear em regressão hedônica, pode apresentar o problema de viés de variável omitida se o modelo não estiver corretamente especificado.

\subsubsection{O método hedônico “Adjacent-Period-Time-Dummy”(APTD)}

A principal crítica ao método TD é a hipótese de que os preços-sombra são constantes no tempo. O método APTD consiste em estimar (3) e (4) a partir de quebras de períodos, no limite estimando uma regressão para cada par de períodos adjacentes. Ou seja, o APTD calcula índices de base móvel, enquanto no TD a base é fixa. A vantagem do APTD é flexibilizar a hipótese de constância dos preços-sombra e amenizar a questão de revisão de índices passados já divulgados. Porém, o método não resolve os problemas relativos à falta de aderência às formulas de índices de preços conhecidas e ao viés de variável omitida.

\subsection{O método hedônico para dados cross-section}

\subsubsection{O método da imputação hedônica}

O método da imputação hedônica (MIH) consiste em utilizar uma regressão hedônica cross-section para cada período de tempo para se imputar o valor de uma cesta de bens observada no período $s$ no período $t$, sendo $s \neq t$. No mercado imobiliário, as vendas de cada unidade não seguem uma frequência pré-definida. Por isso, torna-se impossível construir cestas de imóveis cujas vendas sejam sistemáticas - todo mês, cada três meses, todo ano, etc. O MIH tem como objetivo criar uma cesta de imóveis observável em uma periodicidade definida através da imputação. Com esse procedimento, pode-se calcular as fórmulas de índices conhecidas na literatura como Laspeyres, Paasche, Fisher e Törnqvist.

O método da imputação hedônica parte de um conjunto de regressões hedônicas crosssection para cada período de tempo:

$$
\ln p=Z \beta+\xi
$$

Os parâmetros são estimados para dois períodos de tempo distintos, $s$ e $t$, sendo $s<t$ . Suponha que o imóvel $h$ com características descritas por $z_{c s h}$ (onde $c$ representa a c-ésima característica do imóvel $h$, transacionado no período $s$ ) tenha sido transacionado em $s$, mas

(6) Hill (2013) demonstra que a fórmula do índice TD é um número índice. Porém, não corresponde a nenhuma fórmula consagrada como Laspeyres, Paasche, Fisher, Törnqvist, Jevons, etc. 
não em $t$. Suponha que o preço observado para $h$ no período $s$ seja dado por $p_{s h}$. Como o imóvel $h$ não foi transacionado em $t$, não observamos o preço que $h$ teria no período $t p_{t h}$.

Podemos utilizar uma regressão hedônica com a expressa na equação (5) com imóveis que foram efetivamente transacionados no período $t$ para estimarmos os preços-sombra $\beta_{s}$ associados a cada característica $z_{c t}$ desses imóveis. Uma vez obtidos os preços-sombra, podemos imputar o preço que o imóvel $h$ teria, caso tivesse sido transacionado em $t$. Especificamente, o preço imputado do imóvel $h$ para o período $t$ é dado por: ${ }^{7}$

$$
\hat{p}_{t h}\left(z_{s h}\right)=\exp \left(\sum_{c=1}^{C} \hat{\beta}_{c t} z_{c s h}+\frac{\phi^{2}}{2}\right)
$$

Note que $\hat{p}_{t h}$ é função das características de $h$ observadas no período $s, z_{s h} ; \phi^{2}$ representa a variância do resíduo da regressão expressa em (5), estimada para o período $t$. A variação de preço do imóvel $h$ entre $s$ e $t$ pode então ser calculada pela razão preço imputado em $t$ e preço observado em $s,\left(\frac{\hat{p}_{t h}\left(z_{s h}\right)}{p_{s h}}\right)$, ou pela razão entre o preço imputado em $t$ e o preço previsto para $h$ em $s$, (a partir da equação hedônica tipo 9 para o período $s\left(\frac{\hat{p}_{t h}\left(z_{s h}\right)}{\hat{p}_{s h}\left(z_{s h}\right)}\right)$. O primeiro procedimento é a imputação única e o segundo, a chamada dupla imputação. Hill (2013) e Hill e Melser (2008) argumentam que no caso dos bens imóveis a dupla imputação é o procedimento mais adequado pois é capaz de minimizar o viés de variável omitida ${ }^{8}$.

Após a estimação dos preços imputados, recomenda-se o cálculo dos índices geométricos de Laspeyres e Paasche:

$$
P_{s t}^{G L}=\prod_{h=1}^{H_{s}}\left\{\left[\frac{\hat{p}_{t h}\left(z_{s h}\right)}{\hat{p}_{s h}\left(z_{s h}\right)}\right]^{\frac{1}{H_{s}}}\right\} \text { e } P_{s t}^{G P}=\prod_{h=1}^{H_{t}}\left\{\left[\frac{\hat{p}_{t h}\left(z_{t h}\right)}{\hat{p}_{s h}\left(z_{t h}\right)}\right]^{\frac{1}{H_{t}}}\right\}
$$

onde $P_{s t}^{G L}$ é o índice geométrico de Laspeyres para o período $s$ e $t ; H_{s}$ é o total de imóveis transacionados no período; $P_{s t}^{G P}$ é o índice geométrico de Paasche para o período $s$ e $t$; e $H_{t}$ representa o total de imóveis transacionados em $t$. A partir dos índices geométricos de Paasche e Laspeyres pode-se calcular o índice de Törnqvist que, segundo Hill (2013), é um índice superlativo ${ }^{9}$.

(7) Raciocínio análogo pode ser feito para o imóvel que foi transacionado em $t$ e não em $S$.

(8) Hill e Melser (2008) demonstram, partindo do pressuposto que as características dos imóveis não variam muito em um período curto de tempo, que a dupla imputação minimiza o viés de variável omitida.

(9) O índice superlativo, pela abordagem econômica, é o que representa mais fielmente a variação de preço entre um período e outro já que mantém a utilidade do consumidor constante. Lapeyres e Paasche são casos extremos, e não superlativos, pois não levam em conta o efeito substituição. 
Índice de preços hedônicos para apartamentos: uma aplicação a dados fiscais de Belo Horizonte, 1995-2012

$$
P_{s t}^{T}=\sqrt{P_{s t}^{G L} \times P_{s t}^{G P}}
$$

Hill (2013) enumera como vantagens do método de imputação hedônica:

i) os preços-sombra das características dos imóveis variam com o tempo;

ii) a dupla imputação reduz os efeitos do viés de variável omitida;

iii) permite a utilização de fórmulas padrão de números índices.

Como desvantagens, Hill (2013) cita a falta de interação entre as regressões estimadas para cada período e o fato de, ao contrário dos métodos TD e APTD, os desvios padrões dos índices não serem estimados diretamente, o que torna complexa a tarefa de estimar essas estatísticas.

\subsubsection{O método hedônico das características}

O método hedônico das características (MHC) consiste em um método de imputação pelo imóvel típico. Ao invés de se imputar cada observação, como no método da imputação hedônica (MIH), imputa-se o valor do imóvel pela média ou mediana de suas características. O MHC também se baseia em uma regressão por período, como a representada na equação (6) do MIH. No caso do método hedônico das características, o índice é gerado, por definição, por dupla imputação (Hill, 2013):

$$
\begin{aligned}
& \hat{p}_{t}\left(\bar{z}_{s c}\right)=\exp \left\lfloor\sum_{c=1}^{C}\left(\hat{\beta}_{c t}\right) \bar{z}_{s c}\right\rfloor \\
& \hat{p}_{s}\left(\bar{Z}_{t c}\right)=\exp \left\lfloor\sum_{c=1}^{C}\left(\hat{\beta}_{c s}\right) \bar{z}_{c s}\right\rfloor
\end{aligned}
$$

onde o conjunto de características típicas dos imóveis transacionados em $s$ e $t$ são dados por $\bar{z}_{c s}$ e $\bar{z}_{c t}$, respectivamente.

Os índices de Laspeyres e Paasche estimados pelo MHC são dados por:

$$
P_{s t}^{L}=\frac{\hat{p}_{t}\left(\bar{z}_{s c}\right)}{\hat{p}_{s}\left(\bar{z}_{s c}\right)} \quad \text { e } \quad P_{s t}^{P}=\frac{\hat{p}_{t}\left(\bar{z}_{c t}\right)}{\hat{p}_{s}\left(\bar{z}_{c t}\right)}
$$

Sendo $P_{s t}^{L}$ e $P_{s t}^{P}$ os índices de preço de Laspeyres e Paasche, respectivamente. Hill (2013) recomenda utilizar o índice de Fisher por ser um índice superlativo, que no caso do método hedônico das características é dado por:

$$
P_{s t}^{F}=\sqrt{P_{s t}^{L} \times P_{s t}^{P}}
$$

Em termos conceituais, o índice de Fisher do MHC é muito próximo do índice de Törnqvist do MIH (Hill, 2013). Tanto que as vantagens e desvantagens da aplicação do MHC são as mesmas verificadas no MHC. Hill (2013) adiciona como vantagem do MHC a imputação pelo imóvel típico, por ser um método mais intuitivo. Por outro lado, na construção de índices 
imobiliários o MHC não lida bem com a questão espacial. Não faz sentido mensurar uma localização média ou mediana (Hill, 2013). Por isso, para aplicar o MHC, no caso dos imóveis, é necessário, primeiramente, resolver a questão de como lidar com a tipificação das características espaciais dos imóveis.

\section{3 Índice de preços imobiliários e econometria espacial}

Hill (2013) aventa a possibilidade do uso da econometria espacial para definir as funções hedônicas, aos moldes das especificadas anteriormente nas expressões (3) e (5), e recomenda sua utilização quando há informações na base de dados que identifiquem a localização exata do imóvel. A partir dessa localização é possível identificar as coordenadas geográficas de cada observação permitindo construir a matriz de vizinhança. A intuição dos modelos hedônicos espaciais é que o preço de um determinado imóvel exerce algum tipo de influência no preço dos imóveis vizinhos. A utilização dessa técnica se mostra promissora na medida em que permite estimar parâmetros não viesados e eficientes $(H i l l, 2013)^{10}$. Entretanto, o autor pondera que ainda é incipiente a aplicação de modelos espaciais para estimar índice de preços imobiliários. Os institutos oficiais de estatísticas, por exemplo, utilizam regressões por mínimos quadrados ordinários (OLS) ${ }^{11}$, sendo a inclusão de uma dummy para vizinhança o procedimento mais comumente utilizado para lidar com a natureza espacial do bem imóvel nas estimações oficiais de índice de preços imobiliários. Como será discutido com mais detalhe na seção 3, a base de dados utilizada nesse trabalho não permite que construamos a localização exata de cada observação, impossibilitando a aplicação de estimadores espaciais. Acreditamos, no entanto, que a possibilidade de utilização de modelos de preços hedônicos espaciais é promissora para a construção de um índice de preços de imóveis oficial para o Brasil, ainda que não existam exemplos de índices oficiais estimados a partir de modelos hedônicos espaciais $^{12}$.

\section{Resultados empíricos}

\subsection{Os dados para o mercado imobiliário}

A base de dados do Imposto de Transmissão Imobiliária "Inter-vivos" (ITBI) é considerada a base mais completa para o caso brasileiro em termos de cobertura porque toda transação imobiliária no mercado formal necessita da quitação do ITBI para ser efetivada. A lacuna dessa base é não cobrir o mercado informal de imóveis que, no caso brasileiro, é um

(10) A regressões padrão de econometria espacial podem modelar a relação espacial como uma variável dependente (spatial autoregressive models - SAR), como um componente do resíduo da regressão (spatial error model - SEM) ou admitir a relação espacial em ambos (spatial autoregressive model with autorregressive disturbance - SARAR). Além dessas, há ainda outras técnicas de regressão espacial. Para detalhes ver Almeida (2012) e Golgher (2015).

(11) Enquanto as aplicações de modelos hedônicos espaciais evoluíram bastante nos estudos de formação de preços no mercado imobiliário, o mesmo não ocorreu nas mensurações de índice de preços de imóveis (Hill, 2013, p. 898).

(12) De acordo com Hill (2013), não existem exemplos de índices de preços de imóveis oficiais estimados a partir de modelos hedônicos espaciais. 
mercado relevante (Abramo, 2008). Comparando o ITBI com outras bases existentes, tem-se que os dados extraídos de anúncios de imobiliárias, financiamento imobiliário e lançamentos imobiliários cobrem apenas uma fração do mercado formal. A Pesquisa Nacional por Amostras de Domicílios (PNAD) é a única base de dados que, teoricamente, engloba o mercado informal, porém tanto o desenho da amostra, quanto as variáveis investigadas não são adequadas para o cálculo de índice de preços para imóveis.

Além da cobertura da amostra, que pode gerar um viés de seleção, outra questão importante na análise das bases de dados do mercado imobiliário é o problema de medição do valor do imóvel. O ITBI trabalha com o maior dentre o valor declarado pelo contribuinte e o avaliado pela prefeitura. González (1997b) analisou que o contribuinte - o comprador do imóvel - teria incentivo em subdeclarar o valor para pagar um imposto menor. Porém, existem dois mecanismos que minoram o efeito da subdeclaração. Primeiro, ao impor a alíquota sobre o maior dentre o valor declarado e avaliado, a base apresenta um piso (o valor avaliado) para o preço do imóvel. Isso impede que imóveis da base do ITBI apresentem valores excessivamente baixos. As prefeituras das grandes cidades brasileiras, por sua vez, realizam pesquisas periódicas do valor de mercado dos imóveis para evitar perdas de arrecadação. Por consequência, o valor avaliado é uma boa estimativa do valor do imóvel. Em segundo lugar, a Receita Federal do Brasil (RFB), ao taxar em 15\% o lucro imobiliário, diminui o incentivo do comprador em subdeclarar o valor transacionado, pois em uma futura venda, caso subdeclare o valor da compra, o lucro imobiliário estimado será maior. Ou seja, embora o preço do ITBI esteja sujeito ao problema de medição, esse problema tende a não comprometer significativamente os resultados extraídos dessa base.

As demais bases de dados do mercado imobiliário tendem também a apresentar, em algum grau, o problema da medição. Valores extraídos de ofertas das imobiliárias são enviesados para cima. Dados de financiamento imobiliário, em muito dos casos, utilizam o valor avaliado pelo agente financiador. Já os dados da PNAD dizem respeito ao valor do aluguel que o informante paga (ou atribui) ao imóvel em que ele reside. Desse modo, pelo critério do problema de medição, não existe uma base de dados, para o caso brasileiro, que seja claramente superior à do ITBI.

\subsubsection{A base de dados utilizada}

Para ilustrar o uso de índices hedônicos para o mercado imobiliário, utilizamos a base de dados do Imposto de Transmissão Imobiliária "Inter-vivos" (ITBI) coletado pela Prefeitura Municipal de Belo Horizonte (PBH). Para o nosso trabalho, limitamos a análise às observações referentes a transações imobiliárias com apartamentos. A base foi disponibilizada pela Secretária Municipal de Fazenda da Prefeitura Municipal de Belo Horizonte (SEFAZ-PBH), para o período 1995-2003, e pelo Instituto de Pesquisas Econômicas e Administrativas da 
Universidade Federal de Minas Gerais (IPEAD-UFMG), cobrindo o período 2004-2012. As variáveis informadas na base do ITBI para cada observação são preço, área privativa, ano de construção, padrão de acabamento e bairro. Em decorrência da necessidade legal de se preservar o sigilo fiscal, a base de dados que nos foi fornecida não continha nenhum tipo de informação que permitisse a identificação da unidade imobiliária transacionada. Ou seja, as informações referentes ao endereço completo ou ao índice cadastral municipal do imóvel, que constam na guia do ITBI, não foram disponibilizadas pela SEFAZ/PBH e pelo IPEAD impossibilitando o georreferenciamento da base de dados e a utilização da econometria espacial.

Entre 1995 e 2012 houve 323.168 observações com transações com apartamentos no município de Belo Horizonte. Coulson e McMillen (2006) e González (1997b) apontam que é comum em base de dados do mercado imobiliário a existência de outliers de preço. Analisando especificamente a base de dados do ITBI, González (1997b) admite existirem fatores intrínsecos à base que podem tornar mais aguda a questão dos outliers, como resultado de problemas na transcrição de dados e atualização monetária de valores. A Tabela 1 apresenta um resumo das estatísticas descritivas de preço e área privativa, que ilustra a existência de outliers na base de dados utilizada.

Tabela 1

Estatística descritiva - Preço e área dos apartamentos Belo Horizonte, 1995-2012. Base total

\begin{tabular}{c|c|r|r|r|r}
\hline Variável & \multicolumn{1}{|c|}{ Média } & \multicolumn{1}{c|}{ Mediana } & \multicolumn{1}{c|}{ Mínimo } & \multicolumn{1}{c}{ Máximo } & Desvio-Padrão \\
\hline Preço & $286.311,41$ & $94.578,79$ & 6,17 & $37.000 .000 .000,00$ & $19.594 .710,68$ \\
\hline Área & 124,75 & 103,54 & 0,45 & $51.378,00$ & 135,12 \\
\hline
\end{tabular}

Fonte: Elaboração dos autores a partir dos dados do ITBI/SEFAZ-PBH e do ITBI/IPEAD.

Nota-se que houve registro de imóveis vendidos a $\mathrm{R} \$ 6,17$ e a $\mathrm{R} \$ 37,0$ bilhões. $\mathrm{O}$ primeiro caso trata-se, possivelmente, de um problema de conversão de valores; o segundo, possivelmente um problema de transcrição de dados (González, 1997b). Em decorrência dos outliers, o valor mediano dos apartamentos esteve muito abaixo do valor médio. Em menor escala, os mesmos problemas ocorreram com a variável área, com registro de imóveis com $0,45 \mathrm{~m}^{2}$, em um extremo, e com $51.378 \mathrm{~m}^{2}$, no outro extremo.

Para contornar esse problema, González (1997b) recomenda a detecção de outliers, por meio de gráfico dos logaritmos dos valores. Além dos valores declarados, incluímos também na detecção de outliers, os valores do metro quadrado e área dos imóveis, resultando na eliminação de 1.096 observações. Algumas observações foram eliminadas pela ausência de informação do bairro onde o imóvel se localiza (25 observações), ou pela idade do imóvel estar negativa (11 observações). No total, foram eliminadas 1.132 observações, o que correspondeu a $0,35 \%$ da amostra inicial. A Tabela 2 apresenta os limites adotados para excluir as observações discrepantes. 
Índice de preços hedônicos para apartamentos: uma aplicação a dados fiscais de Belo Horizonte, 1995-2012

Tabela 2

Limite de valores para variáveis valor, área, valor por metro quadrado a partir de análise gráfica de logaritmos

\begin{tabular}{l|r|r}
\hline Variável & Máximo & Mínimo \\
\hline Valor $(\mathrm{R} \$)$ & $3.500 .000,00$ & $8.000,00$ \\
Área $(\mathrm{m} 2)$ & 1.200 & 20 \\
\hline Valor por metro quadrado & $8.200,00$ & 90,00 \\
\hline
\end{tabular}

Fonte: Elaboração dos autores a partir dos dados do ITBI/SEFAZ-PBH e do ITBI/IPEAD.

A base trabalhada (sem outliers) contou com 321.996 observações. A Tabela 3 apresenta as estatísticas descritivas, por ano, para as principais variáveis: preço, área e idade do imóvel (ano da transação subtraído do ano de construção do imóvel) e o número de observações para a base trabalhada. O preço mediano do imóvel passou de $\mathrm{R} \$ 48,3$ mil, em 1995, para R \$270,0 mil, em 2012. A média dos preços foi maior que a mediana para todos anos, o que é característico do mercado imobiliário onde a distribuição dos preços, em geral, apresenta assimetria positiva (Coulson; McMillen, 2006; McMillen, 2008). A área mediana dos imóveis apresentou uma pequena tendência de queda, passando de 113,4 m², em 1995, para 107,0 m²$^{2}$, em 2012. Em relação à idade, observa-se que a mediana passou de 6 anos, em 1995, para 7 anos, em 2012. A distribuição dos valores de área e idade também seguiu o mesmo padrão do valor, exibindo assimetria positiva.

Em relação ao número de transações imobiliárias, o primeiro ano da série, 1995, foi o que registrou o menor número de ocorrências 11.690. O último ano da série, 2012, contou com 18.677 observações, já retirados os outliers. O maior número de transações ocorreu em 2002, (22.064), ano em que o mercado imobiliário sofreu influência das incertezas políticas vigentes no período (Rozenbaum, 2009).

Tabela 3

Estatísticas descritivas por ano para preço, área, idade e número de observações

Belo Horizonte, 1995-2012. Base trabalhada

\begin{tabular}{|c|c|c|c|c|c|c|c|c|c|c|}
\hline \multirow[b]{2}{*}{ Ano } & \multicolumn{3}{|c|}{ Preço (R\$) } & \multicolumn{3}{|c|}{ Área (m2) } & \multicolumn{3}{|c|}{ Idade (anos) } & \multirow[b]{2}{*}{$\begin{array}{l}\text { Número de } \\
\text { observações }\end{array}$} \\
\hline & Médio & Mediano & Desvio Padrão & Médio & Mediano & $\begin{array}{l}\text { Desvio } \\
\text { Padrão }\end{array}$ & Médio & Mediano & $\begin{array}{l}\text { Desvio } \\
\text { Padrão }\end{array}$ & \\
\hline 1995 & $64.991,07$ & $48.326,77$ & $62.597,90$ & 129,86 & 113,67 & 76,82 & 10 & 6 & 10,07 & 11.690 \\
\hline 1996 & $68.401,73$ & $50.000,00$ & $60.771,28$ & 126,72 & 108,75 & 77,57 & 10 & 6 & 10,32 & 13.133 \\
\hline 1997 & $69.646,14$ & $50.850,94$ & $59.178,27$ & 124,99 & 107,14 & 74,04 & 11 & 9 & 10,67 & 15.901 \\
\hline 1998 & $76.769,89$ & $58.000,00$ & $66.989,98$ & 132,30 & 116,00 & 79,79 & 11 & 6 & 10,78 & 15.013 \\
\hline 1999 & $76.195,89$ & $55.500,00$ & $70.124,26$ & 127,55 & 109,17 & 82,36 & 10 & 5 & 10,67 & 15.649 \\
\hline 2000 & $78.318,80$ & $55.000,00$ & $77.482,91$ & 126,34 & 107,32 & 82,12 & 10 & 5 & 11,01 & 17.021 \\
\hline 2001 & $79.726,51$ & $53.000,00$ & $87.406,30$ & 124,90 & 103,43 & 84,34 & 10 & 5 & 11,04 & 16.818 \\
\hline 2002 & $89.700,59$ & $58.808,97$ & $93.550,32$ & 127,17 & 103,29 & 85,56 & 10 & 5 & 11,15 & 22.064 \\
\hline 2003 & $93.637,32$ & $59.591,22$ & $110.000,00$ & 128,82 & 102,20 & 93,00 & 12 & 7 & 11,54 & 19.619 \\
\hline 2004 & $93.478,04$ & $60.000,00$ & $110.000,00$ & 123,53 & 102,00 & 81,66 & 13 & 8 & 11,86 & 18.149 \\
\hline 2005 & $96.196,12$ & $61.010,84$ & $120.000,00$ & 120,22 & 98,53 & 78,76 & 14 & 10 & 12,12 & 20.167 \\
\hline 2006 & $110.000,00$ & $70.000,00$ & $130.000,00$ & 122,53 & 101,79 & 82,31 & 14 & 10 & 12,32 & 19.134 \\
\hline 2007 & $130.000,00$ & $82.307,47$ & $150.000,00$ & 121,95 & 102,76 & 75,51 & 14 & 10 & 12,28 & 19.928 \\
\hline 2008 & $160.000,00$ & $100.000,00$ & $180.000,00$ & 122,84 & 101,37 & 78,20 & 14 & 10 & 12,51 & 19.471 \\
\hline 2009 & $190.000,00$ & $130.000,00$ & $210.000,00$ & 119,78 & 98,52 & 78,31 & 14 & 10 & 12,85 & 18.552 \\
\hline 2010 & $230.000,00$ & $160.000,00$ & $230.000,00$ & 115,76 & 94,00 & 76,28 & 12 & 8 & 13,05 & 21.477 \\
\hline 2011 & $310.000,00$ & $220.000,00$ & $290.000,00$ & 120,60 & 97,86 & 79,15 & 12 & 7 & 13,32 & 19.573 \\
\hline 2012 & $370.000,00$ & $270.000,00$ & $330.000,00$ & 126,09 & 107,00 & 80,02 & 12 & 7 & 13,53 & 18.677 \\
\hline
\end{tabular}

Fonte: Fonte: Elaboração dos autores a partir dos dados do ITBI/SEFAZ-PBH e do ITBI/IPEAD. 
Cada apartamento de Belo Horizonte é classificado pela prefeitura quanto ao seu padrão de acabamento. Há cinco padrões, em ordem crescente de sofisticação: popular, baixo, normal, alto e luxo. A Tabela 4 apresenta a distribuição percentual de cada tipo de apartamento na base trabalhada. Em todo o período, imóveis do padrão normal foram os predominantes. Seguidos de apartamentos de padrão alto (22,2\% na média do período) e baixo (20,8\% na média do período). Em apenas 1995 e 1996, os dois primeiros anos da série, a participação de apartamentos de padrão normal ficou abaixo de 50\%. Os imóveis de padrão luxo ganharam participação ao longo do período, passando de 1,1\% em 1995 para 5,4\% em 2012.

Tabela 4

Distribuição dos padrões de acabamento por ano das transações imobiliárias com apartamentos Belo Horizonte, 1995-2012. Base trabalhada

\begin{tabular}{|c|c|c|c|c|c|}
\hline Ano & Luxo & Alto & Normal & Baixo & Popular \\
\hline 1995 & 1,11 & 30,83 & 48,55 & 19,32 & 0,19 \\
\hline 1996 & 0,43 & 28,47 & 46,76 & 24,25 & 0,08 \\
\hline 1997 & 0,18 & 24,12 & 53,36 & 22,24 & 0,09 \\
\hline 1998 & 0,67 & 27,11 & 54,48 & 17,68 & 0,06 \\
\hline 1999 & 1,16 & 25,06 & 54,41 & 19,31 & 0,06 \\
\hline 2000 & 3,03 & 19,95 & 56,55 & 20,13 & 0,34 \\
\hline 2001 & 3,56 & 17,64 & 57,77 & 19,98 & 1,06 \\
\hline 2002 & 4,46 & 20,71 & 55,36 & 18,43 & 1,04 \\
\hline 2003 & 3,80 & 18,28 & 56,85 & 20,19 & 0,87 \\
\hline 2004 & 2,98 & 16,72 & 59,65 & 19,97 & 0,68 \\
\hline 2005 & 2,86 & 15,44 & 58,80 & 22,14 & 0,76 \\
\hline 2006 & 3,40 & 16,39 & 57,44 & 21,87 & 0,89 \\
\hline 2007 & 3,46 & 16,72 & 60,28 & 18,67 & 0,88 \\
\hline 2008 & 3,88 & 17,42 & 59,17 & 18,66 & 0,87 \\
\hline 2009 & 3,03 & 16,80 & 58,35 & 20,66 & 1,16 \\
\hline 2010 & 3,38 & 18,35 & 58,25 & 19,10 & 0,93 \\
\hline 2011 & 4,76 & 23,27 & 55,48 & 15,56 & 0,93 \\
\hline 2012 & 5,39 & 23,18 & 56,84 & 13,72 & 0,86 \\
\hline
\end{tabular}

Fonte: Elaboração dos autores a partir dos dados do ITBI/SEFAZ-PBH e do ITBI/IPEAD.

\subsection{Especificação dos modelos}

Os modelos foram especificados pela forma funcional semilogarítmica (Hill, 2013), tendo como variável explicada o logaritmo do preço dos imóveis. As variáveis explicativas, Z, são as características dos imóveis contidas na base de dados do ITBI. O acabamento foi um conjunto de variáveis do tipo dummy para cada padrão de acabamento, tendo como categoriabase o padrão "Normal". Como os dados não são georeferenciados, o controle para localização foi realizado através de um conjunto de variáveis do tipo dummy para cada Área de Ponderação (AP), tendo a AP "Savassi" como categoria-base ${ }^{13}$. Foram incluídas ainda as variáveis área e idade em nível e elevadas ao quadrado ${ }^{14}$. Os modelos time-dummy (TD) e adjacent-period-

(13) Belo Horizonte possui 62 AP's que são compostas por um conjunto de bairros.

(14) As regressões foram estimadas por mínimos quadrados ordinários com desvios padrões robustos para clusters de bairros. As saídas das regressões encontram-se com o autor. 
time-dummy (APTD) foram especificados com efeitos fixos para acabamento, localização (AP's) e tempo:

$$
\begin{aligned}
& \ln p_{i, j, t}=Z_{i, t} \beta_{i}+\gamma_{i, j} B_{j}+\delta_{t} t+\xi_{t} \\
& \left(\ln p_{i, j, t}=Z_{i, t} \beta_{i, t}+\gamma_{i, j, t} B_{i, j, t}+\delta_{t+1} t+\xi_{i, j, t}\right)^{y, t_{+1}}
\end{aligned}
$$

onde, $p$ é o preço do imóvel $i$, localizado em $j$ e transacionado em $t$. $Z$ é o conjunto de variáveis explicativas, incluindo o acabamento; $\beta$ representa os preços-sombra de cada característica de $Z$; B são as dummies de localização (AP's); $\gamma$ representa os preços-sombra de cada localização; $t$ é a dummy para o tempo; $\delta$ é o parâmetro a ser estimado para o tempo; e $\xi$ o resíduo aleatório da regressão ${ }^{15}$.

Os métodos MIH e MHC utilizam um conjunto de regressões estimadas com efeitos fixos para acabamento e localização, como nas expressões abaixo:

$$
\begin{aligned}
& \left(\ln p_{i, j}=Z_{i} \beta+\gamma_{j} B_{i, j}+\xi_{i}\right)^{\prime} \\
& \left(\ln p_{i, j}=Z_{i} \beta+\gamma_{j} B_{i, j}+\xi_{i}\right)^{t, k}
\end{aligned}
$$

Para contornar o problema da localização média do método hedônico das características (MHC), o método foi estimado para cada conjunto $k$ de 32 localizações, que correspondem às AP's ou agregações de AP's ${ }^{16}$. O índice de preço para o método da imputação hedônica (MIH) é o da expressão (8). O índice do MHC foi calculado a partir do valor estimado do preço para cada AP - pelos valores medianos de área e idade, para a moda do acabamento e incluindo o parâmetro estimado para a AP, a partir da regressão (18). Posteriormente, o índice do município foi calculado pela participação de cada região $k$ no total do valor das transações do município. O índice do MHC para o município de Belo Horizonte foi dado por:

$$
P_{s t, B H}^{F}=\sum_{k=1}^{K} \frac{1}{w_{k, s t}}\left(P_{s t, k}^{F}\right)
$$

Sendo $B$ o conjunto das localizações da cidade $(k), B H$ representa o índice para o município e $w$ o peso de cada localização no total do valor das transações imobiliárias da cidade.

(15) O sufixo $t, t+1$ na regressão 16, método APTD, indica que um conjunto de regressões é estimado para cada par de período de tempo.

(16) Algumas AP's foram agregadas para que se tivessem observações suficientes em cada ano para estimar o modelo de regressão. 


\subsection{Resultados e comparação dos índices}

O Gráfico 1 apresenta os índices estimados pelos diversos métodos hedônicos. A Tabela 5 apresenta as valorizações nominais anuais calculadas a partir dos diversos métodos testados. A valorização dos apartamentos em Belo Horizonte entre 1995 e 2012 foi estimada em $546,72 \%$ pelo método TD, $563,11 \%$ pelo APTD, $567,94 \%$ pelo MIH e 588,97\% pelo MHC.

Tabela 5

Valorização anual dos apartamentos em Belo Horizonte para diferentes métodos hedônicos $-1995-2012$

\begin{tabular}{|c|c|c|c|c|}
\hline Ano & TD & APTD & MIH & MHC \\
\hline 1996 & 12,19 & 12,01 & 11,74 & 7,52 \\
\hline 1997 & 8,88 & 8,86 & 10,82 & 10,92 \\
\hline 1998 & 1,07 & 1,48 & 1,85 & 2,98 \\
\hline 1999 & 1,21 & 0,94 & 1,00 & 2,55 \\
\hline 2000 & 3,00 & 2,82 & 2,21 & 1,06 \\
\hline 2001 & 1,76 & 1,79 & 1,58 & 2,07 \\
\hline 2002 & 6,89 & 7,08 & 6,42 & 3,98 \\
\hline 2003 & 4,84 & 5,19 & 5,44 & 5,70 \\
\hline 2004 & 5,90 & 6,45 & 6,50 & 7,39 \\
\hline 2005 & 7,35 & 7,89 & 7,93 & 11,00 \\
\hline 2006 & 12,27 & 12,20 & 12,53 & 13,22 \\
\hline 2007 & 18,27 & 18,13 & 18,60 & 19,44 \\
\hline 2008 & 22,66 & 22,48 & 23,81 & 24,76 \\
\hline 2009 & 27,53 & 27,31 & 28,42 & 30,68 \\
\hline 2010 & 26,38 & 27,93 & 25,76 & 25,89 \\
\hline 2011 & 25,71 & 26,32 & 25,80 & 24,53 \\
\hline 2012 & 17,46 & 17,42 & 16,64 & 17,11 \\
\hline Média 1996-2004 & 5,02 & 5,12 & 5,22 & 4,86 \\
\hline Média 2005-2012 & 19,51 & 19,76 & 19,74 & 20,66 \\
\hline Média 1996-2012 & 11,61 & 11,77 & 11,82 & 12,02 \\
\hline Total do Período & 546,72 & 563,11 & 567,94 & 588,97 \\
\hline Fonte: & & & & \\
\hline
\end{tabular}

Fonte: Elaboração dos autores a partir dos dados do ITBI/SEFAZ-PBH e do ITBI/IPEAD.

Como mostra o Gráfico 1, as curvas para os índices de preços estimados pelos diversos métodos são similares entre si principalmente quando os preços são relativamente estáveis. A partir de 2005, verifica-se que a curva se torna mais íngreme para todos os métodos. Ou seja, no período de valorização imobiliária mais intensa, os diversos índices passam a diferir um pouco, com o obtido pelo método hedônico das características (MHC) indicando a valorização relativamente mais intensa. Esse efeito sobre o MHC pode ter resultado da especificação do modelo. Isso porque, enquanto os métodos TD, APTD e MIH foram estimados a partir de regressões para todo o município, o MHC estimou regressões para cada $\mathrm{AP}$ ou conjunto de AP's. Com isso, as regressões em cada ano foram obtidas em alguns domínios com poucas observações e o ajuste de algumas delas ( $\mathrm{R}^{2}$-ajustado e significância dos parâmetros) não foi satisfatório. 
Gráfico 1

Índice de preços para apartamentos, diversos métodos hedônicos - Belo Horizonte, 1995-2012

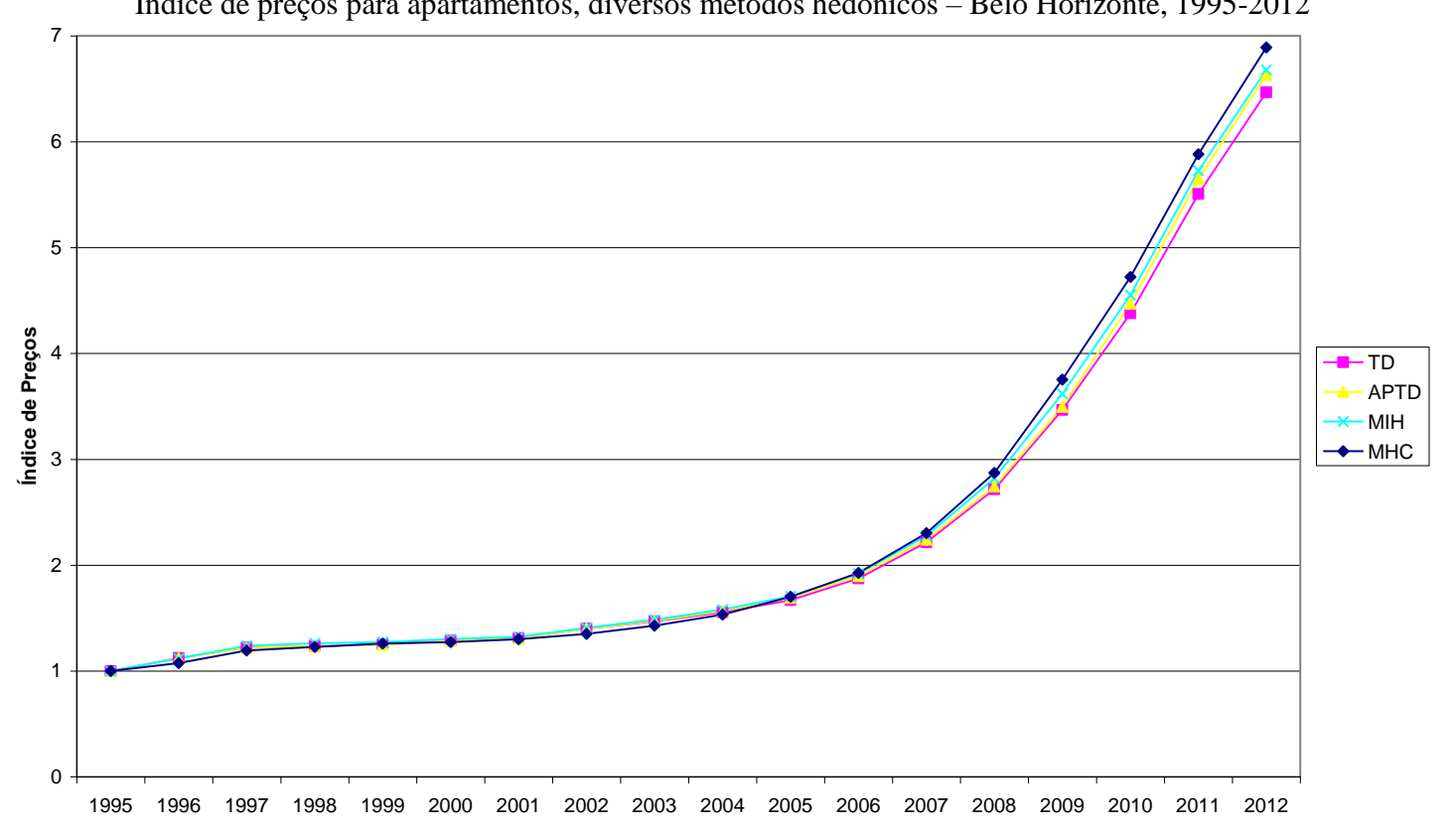

Fonte: Elaboração dos autores a partir dos dados da SEFAZ/PBH e IPEAD/UFMG.

A curva do método TD ficou abaixo das curvas APTD e MIH nos últimos anos. Esse resultado não surpreende, uma vez que o método TD tem como hipótese que os preços-sombra das características não se alteram ao longo do tempo. Como no caso dos imóveis há rigidez no estoque de bens a curto-prazo, esse método é comumente utilizado para períodos relativamente curtos. ${ }^{17}$ Porém, para períodos mais longos passa a ser forte a hipótese de que as condições da oferta e da demanda permaneçam constantes no tempo. A partir de 2005, as curvas do APTD e MIH se descolam da curva TD, evidenciando ser o período estudado (1995-2012) muito longo para a aplicação do time-dummy. Por outro lado, as curvas do APTD e MIH, se aproximaram ao longo do tempo. Esse resultado é esperado, dado que os dois métodos são bastante flexíveis quanto à mensuração dos preços-sombra das características ao longo do tempo. Alguns autores associam matematicamente o MIH como um caso limite do APTD, na medida em que os períodos adjacentes se tornam cada vez mais próximos. Nesse sentido, o índice estimado a partir do método APTD teria alguma relação com a fórmula do índice de Törnqvist, que é o obtido pelo MIH (Haan, 2004).

Na comparação entre o APTD e o MIH tem-se que ambos respeitam o critério de estabilidade temporal (temporal fixty) para avaliar adequação de índices de preços, segundo o

(17) No caso dos bens de alta tecnologia, a hipótese de que os preços-sombra das características não se alteram no tempo é considerada muito forte e a literatura especializada descarta a utilização desse método (Triplett, 2004). 
qual ao se divulgar índices para novos períodos de tempo os valores já divulgados não se alteram (Hill, 2004). O MIH tem como vantagens gerar um índice de Törnqvist, cuja fórmula além de ser previamente conhecida na literatura é reconhecida como um índice superlativo, como discutido anteriormente. Por esses motivos, o índice MIH é comumente tido como padrão ou benchmark (Waltl, 2016).

\subsection{O comportamento do mercado imobiliário e a conjuntura econômica}

O Gráfico 2 ilustra o comportamento dos preços dos imóveis em Belo Horizonte, 19952012, em relação a alguns indicadores de conjuntura econômica ${ }^{18}$. Verifica-se que após um período de crescimento real do preço dos imóveis (1995-1998), a valorização imobiliária em termos nominais foi menor que a inflação (período 1999-2004). O período de menor valorização real foi 2001-2003 marcado pela grande queda no volume de crédito imobiliário. Entre 2001 e 2004, a valorização imobiliária acompanhou os ganhos de renda da população da Região Metropolitana de Belo Horizonte (RMBH). Por fim, a taxa básica de juros da economia (Selic) esteve em um patamar relativamente elevado no período 1996-2004 (25,24\% ao ano, em média), contribuindo para inibir a valorização imobiliária.

O período 2005-2012 caracterizou-se pela curva de valorização imobiliária nominal estar bastante acima da curva da inflação. Essa intensa valorização imobiliária nominal (19,74\% a.a., em média) foi contemporânea a um crescimento no volume de crédito imobiliário nominal a taxas ainda maiores (33,94\% a.a., em média). Segundo Aguiar (2014), um fator fundamental para o crescimento do crédito imobiliário no período em questão foi a aprovação da lei n. 10.931 de 2004, que viabilizou a aplicação do instituto da alienação imobiliária criado em 1997. A regulamentação desse instituto aumentou sensivelmente a segurança jurídica dos contratos de financiamento imobiliário, do ponto de vista do ofertante de crédito. Contribuiu também para o crescimento tanto dos preços dos imóveis quanto do crédito imobiliário, a trajetória de queda da taxa Selic cuja média anual entre 2005 e 2012 foi 12,24\% a.a., relativamente baixa para o período da nossa amostra de dados. Por fim, embora a renda média da população da RMBH tenha aumentado entre 2005 e 2012, sua taxa de crescimento esteve em patamar notadamente menor que o da valorização imobiliária.

(18) Nessa e nas próximas seções, os índices e estatísticas utilizados derivam das seguintes fontes: inflação, medida pelo Índice de Preços ao Consumidor Amplo (IPCA) anual medida pelo IBGE e extraída do IPEAdata (www.ipeadata.gov.br); Selic é a taxa de juros Over/Selic nominal mensal do Boletim do Banco Central, extraída do IPEAdata; renda nominal é a renda nominal mensal da Região Metropolitana de Belo Horizonte, medida pela Pesquisa Mensal do Emprego (PME) do IBGE, extraída da base SIDRA do IBGE (www.ibge.gov.br); e volume do crédito imobiliário foi extraído das operações de crédito imobiliário ao setor privado, em termos nominais, da seção Moeda e Crédito do Banco Central disponível no IPEAdata. 
Gráfico 2

Valorização imobiliária anual (MIH) X Indicadores macroeconômicos

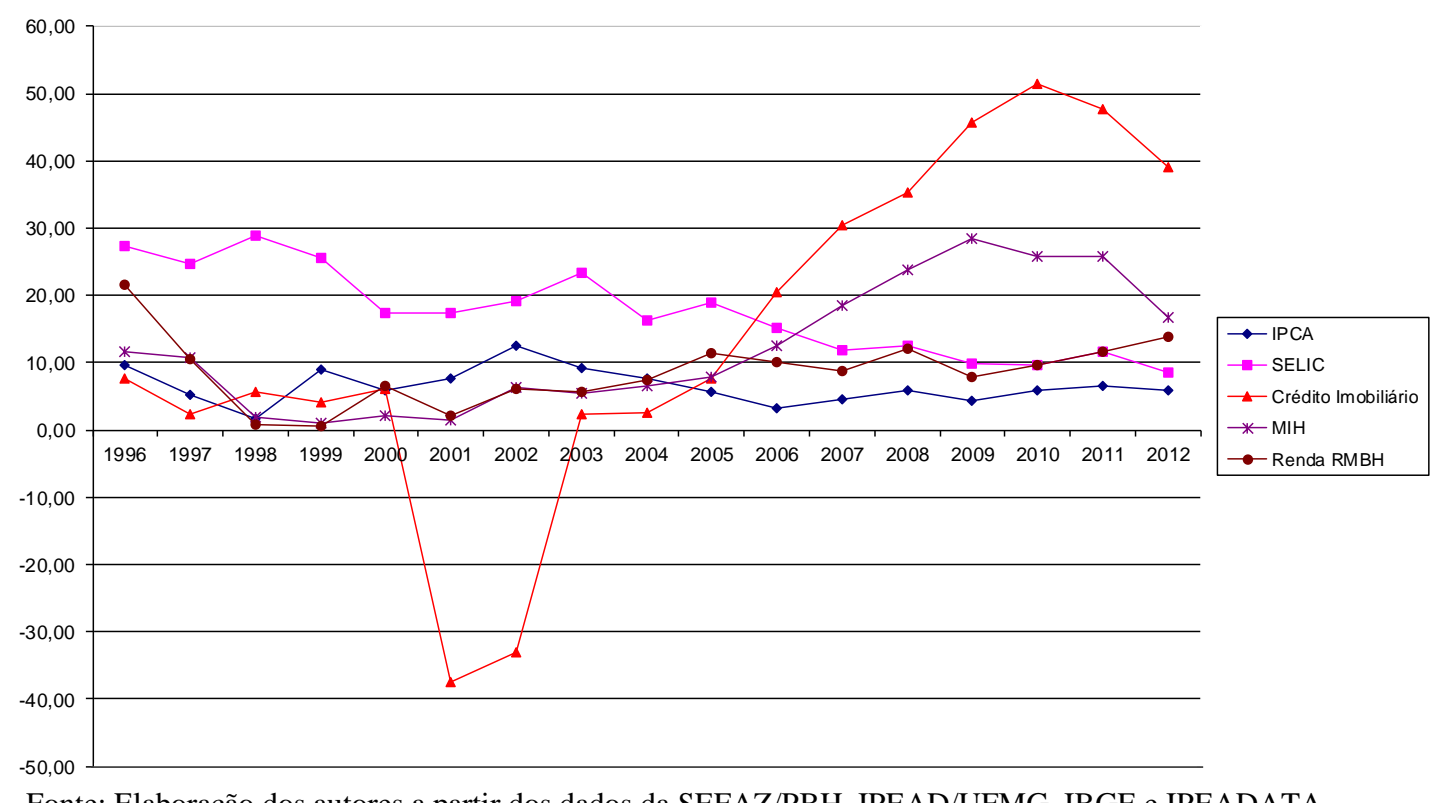

Fonte: Elaboração dos autores a partir dos dados da SEFAZ/PBH, IPEAD/UFMG, IBGE e IPEADATA.

\subsection{Comparação com IVG-R}

Após a escolha do índice e uma interpretação de sua dinâmica frente à conjuntura econômica da época, vamos comparar esse índice com um outro já existente e que seja mensurado por outra metodologia. O Banco Central do Brasil (BCB) publica o Índice de Valores de Garantia de Imóveis Residenciais Financiados (IVG-R) desde abril de 2013, com dados a partir de março de 2001. O IVG-R é um índice estimado a partir de métodos estratificados tendo como parâmetro a mediana dos preços por localização. O IVG-R difere dos índices hedônicos aqui estimados pela metodologia e pela base de dados utilizada. Enquanto utilizamos a base de dados do ITBI, o BCB utilizou a base de dados dos financiamentos imobiliários executados pelas instituições financiadoras. Como discutido anteriormente, o ITBI contém o universo das transações no mercado formal, que é um subconjunto do total de transações imobiliárias. Já o IVG-R trabalha com o universo das transações financiadas, que corresponde a um subconjunto do universo das transações que ocorrem no mercado formal. Por fim, o IVG-R é um índice para o Brasil, enquanto o MIH aqui mensurado é para o município de Belo Horizonte. Embora possa haver idiossincrasias locais, a taxa básica de juros, a política de crédito imobiliário e o ambiente macroeconômico (que determina o crescimento do produto e da renda), variáveis que influenciam a dinâmica do preço dos imóveis, são determinados em nível nacional. 
Como a série do IVG-R se inicia em março de 2001, a comparação entre o MIH e o IVG-R será feita para o período 2002-2012. O Gráfico 3 apresenta a série dos dois índices medidos em valorização anual, em termos nominais.

Gráfico 3

Índice de preço hedônico para Belo Horizonte (MIH) X IVG-R - Valorizações anuais

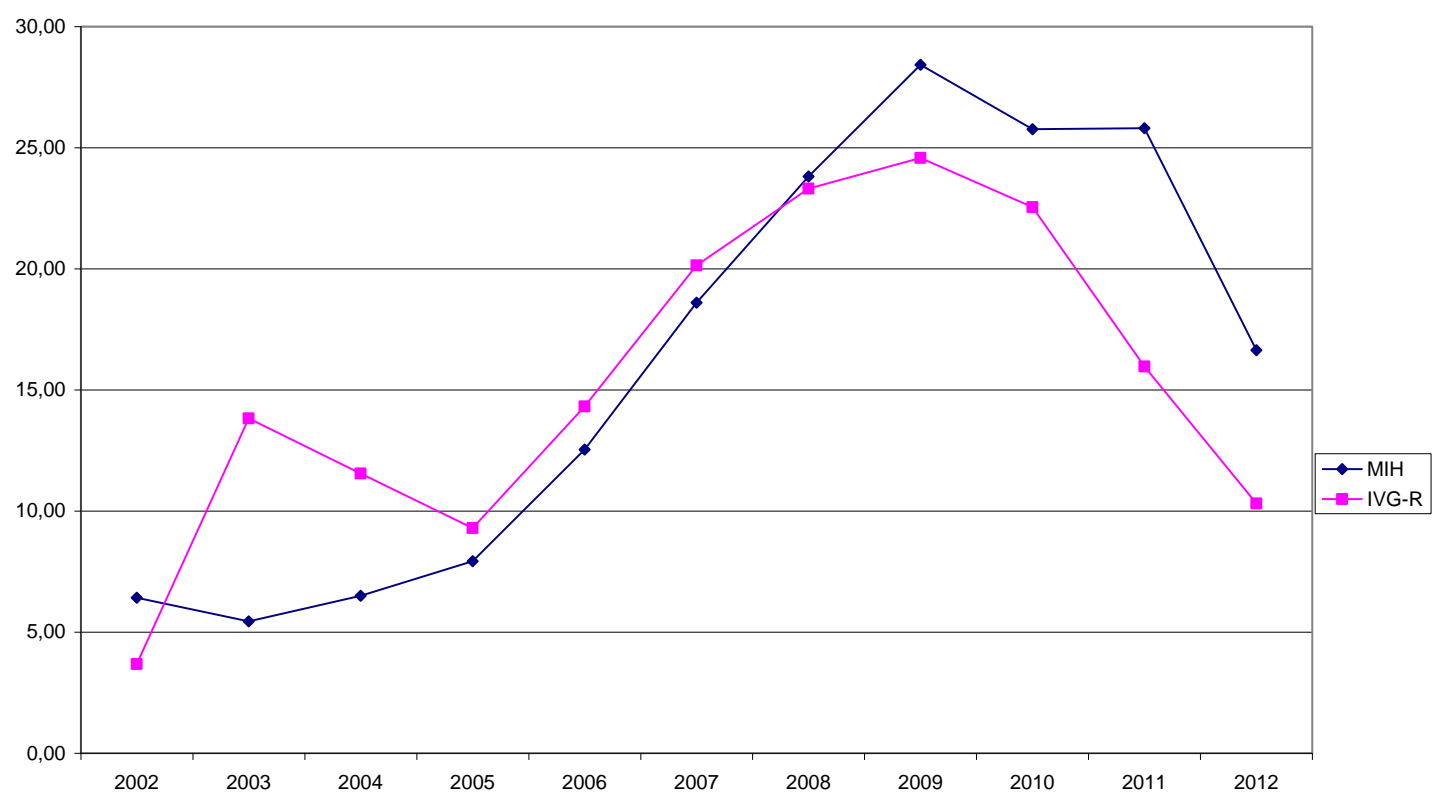

Fonte: SEFAZ/PBH, IPEAD/UFMG e Banco Central do Brasil.

Pelo Gráfico 3, entre os anos de 2005 e 2008 os índices apresentaram uma trajetória semelhante. Esse período foi um período marcado pelo bom desempenho da economia com o PIB crescendo a uma taxa média de $4,6 \%$, inflação bem comportada (4,8\% em média), aumento da renda e disponibilidade de crédito imobiliário (aumento médio de 33,6\%). Nos períodos 2002-2004 e 2009-2012, no entanto, os índices estiveram descolados. No primeiro caso (20022004), o deslocamento parece ser fruto da base de dados utilizada. No ano de 2002, por exemplo, as operações de crédito imobiliário caíram em 33,02\%, em relação a 2001, que já havia registrado uma queda de 37,42\%, em relação a 2000. Ou seja, o período 2002-2004 foi marcado por poucas operações de crédito imobiliário, o que leva a crer que o índice calculado pelo IVG-R esteja sofrendo de um viés de seleção. Com poucos financiamentos imobiliários, o universo das transações imobiliárias passou a ser uma fração pequena do mercado de transações formais. Portanto, as operações de financiamento, em um mercado marcado por regras ainda não bem definidas e taxa de juros elevadas, podem ter se concentrado em imóveis de maior valor.

No segundo caso, período 2009-2012, os dois índices apontam para uma desaceleração na taxa de valorização imobiliária, porém, o IVG-R reflete uma desaceleração maior. Em 2009, 
a crise mundial iniciada em 2008 fez-se sentir no Brasil. A equipe econômica do Governo brasileiro elaborou um conjunto de políticas anticíclicas para combater os efeitos da crise. Dentre essas políticas estavam o aumento do crédito imobiliário por parte dos bancos públicos (Caixa Econômica Federal e Banco do Brasil) e aporte a programas de construção de moradias para população de baixa renda (Programa Minha Casa, Minha Vida). Nesse contexto, os anos de 2009-2012 foram os de maior aumento no crédito imobiliário do período (média de 45,89\%). A desaceleração da valorização imobiliária parece estar refletindo a mudança de foco do financiamento imobiliário. Ao invés de se concentrar no mercado de maior poder aquisitivo, o financiamento imobiliário se concentrou em imóveis para a população de menor poder aquisitivo. Pode se supor que, nesse contexto, o IVG-R, por não controlar a variação de preços pelas características dos imóveis, superestimou a desaceleração dos preços. Em contrapartida, o MIH foi mais eficaz em controlar o efeito composição resultante da mudança no perfil dos imóveis transacionados. No caso de Belo Horizonte, a partir de 2009, essa mudança na composição das características dos imóveis transacionados foi refletida na redução da área mediana, maior incidência de imóveis de acabamento "Baixo" e localizados em regiões periféricas.

\section{Conclusão}

O presente trabalho teve como objetivo discutir as metodologias hedônicas mais utilizadas para a mensuração de índice de preços para imóveis. Os quatro métodos de estimação de índice de preços imobiliários: time-dummy (TD), adjacent-period-time-dummy (APTD), método da imputação hedônica (MIH) e método hedônico das características (MHC) foram apresentados, discutidos e aplicados para uma base de dados de imóveis para Belo Horizonte. O objetivo da aplicação dos índices hedônicos para um caso específico é poder comparar seus resultados para um período cujas características macroeconômicas já foram observadas.

Dos diversos métodos, o MIH foi escolhido como benchmark. O método de cálculo do $\mathrm{MIH}$, assim como o do APTD e o do MHC, é flexível quanto a mudanças nos padrões de oferta e demanda dos imóveis ao longo do tempo. Assim como o APTD, ao contrário do MHC, o ajuste das regressões, em termos de significância dos parâmetros estimados e $\mathrm{R}^{2}$-ajustado, se mostrou satisfatório. Por fim, embora a trajetória do APTD e MIH tenham ficado muito próximas, a escolha do MIH se baseia no fato deste, ao contrário do APTD, seguir uma fórmula padrão (e superlativa) da literatura de índice de preços (Törnqvist).

Verificou-se que a valorização imobiliária em Belo Horizonte se acelerou a partir de 2005, após a regulamentação, em 2004, do instituto da alienação fiduciária. Entre 1995 e 2004, a valorização imobiliária foi pequena, na maior parte do período abaixo da inflação. A conjuntura desse período foi marcada pelo patamar relativamente elevado da taxa básica de juros e pelo pequeno volume do crédito imobiliário. Já no período 2005-2012, a valorização imobiliária real foi intensa, o mesmo ocorrendo com a expansão do crédito imobiliário. Também contribuíram para esse cenário o crescimento do PIB, a redução da taxa básica de juros e o aumento da renda real das famílias. Entre 2008 e 2011, os preços dos apartamentos 
cresceram a taxas acima dos $20 \%$ anuais, em termos nominais. Em 2009, essa valorização atingiu seu pico, $28,42 \%$. A trajetória de valorização imobiliária em BH tornou-se um pouco menos intensa, mas não foi interrompida pela crise mundial de 2008/2009. Uma das razões é que dentre as políticas anticíclicas adotadas pelo governo federal, muitas beneficiaram o mercado imobiliário, como o aumento do crédito imobiliário para os bancos públicos e o programa habitacional Minha Casa, Minha Vida.

Em termos de proposição de políticas, a provisão de informação sobre a valorização imobiliária é uma importante ferramenta para a política macroeconômica do governo central e para políticas urbanas dos governos locais. A trajetória do preço dos imóveis é um importante parâmetro para subsidiar o controle da inflação, elaborar políticas macroprudenciais (visando evitar crises financeiras e bolhas imobiliárias) e para elaborar políticas de financiamento imobiliário de habitação social. No caso dos governos locais, o monitoramento do preço dos imóveis nas diversas regiões da cidade pode servir como subsídio tanto para a proposição quanto para a avaliação dos efeitos de políticas públicas, motivos que realçam a importância de se avançar na discussão sobre a construção de um índice oficial de preços para imóveis no Brasil.

Os índices estimados nesse trabalho constituem um importante subsídio nessa discussão. Primeiramente, esse trabalho ressalta a potencialidade da utilização da base de dados do ITBI para essa tarefa. Por abranger o universo das transações imobiliárias formais e estar disponível no banco de dados das prefeituras, essa base mostra-se a mais promissora para um índice nacional. Somado a isso, o trabalho demonstra ser viável a aplicação da metodologia hedônica, reconhecida internacionalmente como a mais adequada, para estimar índice de preços, a partir da base de dados do ITBI. A comparação do índice hedônico MIH, aqui estimado, com o IVG-R, índice divulgado pelo Banco Central do Brasil estimado pela metodologia da mediana estratificada aplicada a uma base de financiamentos imobiliários, demonstrou que o índice hedônico aplicado à base do ITBI apresentou maior estabilidade. Esse comportamento se deve tanto à base de dados do ITBI ser mais abrangente, quanto da metodologia hedônica controlar o efeito composição das características dos imóveis. Nos anos 2001 e 2002, a grande oscilação do IVG-R, em relação ao MIH, deveu-se à limitação da base de dados. Como nesses anos o volume de crédito imobiliário sofreu dois grandes choques negativos, o financiamento se tornou um subconjunto diminuto do universo das transações imobiliárias formais. Entre 2009 e 2012, a queda na valorização imobiliária estimada pelo IVG$\mathrm{R}$ foi muito mais aguda que a estimada no MIH. Nesse caso, como políticas governamentais visaram estimular o crédito imobiliário para imóveis de menor valor, a metodologia hedônica se mostrou mais robusta justamente por permitir incorporar a mudança no perfil das características dos imóveis transacionados.

Por fim, pesquisas futuras poderiam aplicar essa pesquisa para outras cidades brasileiras, permitindo que estudos comparativos estabeleçam os traços comuns e as peculiaridades locais na valorização imobiliária. Do ponto de vista metodológico, técnicas de econometria espacial poderão ser utilizadas para construção de índice de preços imobiliários, 
na medida que bases de dados georreferenciadas sejam disponibilizadas. O uso do ferramental da econometria espacial será útil para avaliar até que ponto a incorporação dessas técnicas é útil em gerar índices de preços mais robustos.

\section{Referências bibliográficas}

ABRAMO, Pedro. A cidade Com-fusa: a mão inoxidável do mercado e a produção da estrutura urbana nas grandes metrópoles latino-americanas. Revista Brasileira de Estudos Urbanos e Regionais, v. 5, 2008.

ALMEIDA, Eduardo. Econometria espacial aplicada. São Paulo: Alinea, 2012.

AGUIAR, Marina Moreira de. Crédito e mercado imobiliário no Brasil: fatores institucionais e macroeconômicos (1964-2013). In: SEMINÁRIO DE ECONOMIA MINEIRA, 16, Diamantina, 2014. Anais... Diamantina: Cedeplar/UFMG, 2014.

BAILEY, Martin J.; MUTH, Richard F.; NOURSE, Hugh O. A regression method for real estate price index construction. Journal of the American Statistical Association, v. 58, n. 34, p. 933-942, 1963.

BIANCONI, Marcelo; YOSHINO, Joe A. House price indexes and cyclical behavior. International Journal of Housing Markets and Analysis, v. 6, n. 1, p. 26-44, 2013.

COULSON, Nelson Edward; McMILLEN, Daniel. Quantile house price indexes. In: THE AMERICAN REAL ESTATE AND URBAN ECONOMICS ASSOCIATIOS (AREUEA) ANNUAL CONFERENCE, Boston, 2006. Anais... Boston: AREUEA, 2006. Available at: http://www.areuea.org/conferences/pdf/52/735.doc. Available at: Dec. 2014.

COURT, Andrew. Hedonic price indexes with automotive examples. In: THE DYNAMICS of automobile demand. New York: General Motors, 1939. p. 98-119.

DIEWERT, W. Erwin. The Paris OECD-IMF Workshop on Real Estate Price Indexes: conclusions and future directions. In: DIEWERT, E. Erwin et al. (Ed.). Price and productivity measurement. v. 1 - Housing. Trafford Press, 2009. Available at: http://faculty.arts.ubc.ca/ediewert/dp0701.pdf. Acesso em: Feb. 2010

GATZLAFF, Dean H; LING, David C. Measuring changes in local house prices: an empirical investigation of alternative methodologies. Journal of Urban Economics, v. 35, p. 221-244, 1994.

GOLGHER, Andé Braz. Introdução à econometria espacial. Jundiaí: Paco Editora, 2015.

GONZÁLEZ, Marco Aurélio Stumpf. Variação qualitativa e índice de preços na análise do comportamento recente dos aluguéis em Porto Alegre (1994-1997). Análise Econômica, v. 15, n. 28, 1997a. 
GONZÁLEZ, Marco Aurélio Stumpf. Fonte alternativa para estudos intraurbanos: ITBI. In: ENCONTRO NACIONAL DA ANPUR, 7, 1997, Recife. Anais... Recife: Associação Nacional de Pós-Graduação em Planejamento Urbano e Regional, 1997b.

GRILICHES, Zvi. The demand for fertilizer: an econometric reinterpretation of a technical change. Journal of Farm Economics, v. 40, n. 31, p. 591-606, 1958.

GRILICHES, Zvi. Hedonic price indexes for automobiles: an econometric of quality change. In: THE PRICE statistics of the Federal Government. New York: Columbia Univ. Press for the National Bureau of Economic Research, 1961. p. 137-196. (General Series, n. 73).

GRILICHES, Zvi. Introduction: hedonic price indexes revisited. In: GRILICHES, Zvi (Ed.). Prices indexes and quality change: studies in new methods of measurement. Cambridge: Harvard University Press, 1971.

HAAN, Jean de. Hedonic regressions: the time dummy index as a special case of the Törnqvist Index, time dummy approaches to hedonic price measurement. Paper presented at the Eighth Meeting of the International Working Group on Price Indices, Aug. 23-25 (Helsinki: Statistics Finland), 2004. Disponível em: http://www.stat.fi/og2004/dehaanp_ver2.pdf. Available at: Dec. 2014.

HILL, Robert. Constructing price indexes across the space and time: the case of European Union. American Economic Review, v. 94, n. 5. p. 1379-1410, 2004.

HILL, Robert. Hedonic price indexes for residential housing: a survey, evaluation and taxonomy. Journal of Economic Surveys, v. 27, n. 1, p. 879-914, 2013.

HILL, Robert; MELSER, Daniel; SYED, Iqbal. Measuring a boom and bust: the Sydney housing market 2001-2006. Journal of Housing Economics, v. 18, n. 3, p. 193-225, 2009.

HILL, Robert; MELSER, Daniel. Hedonic imputation and the price index problem: an application to housing. Economic Inquiry, v. 46, n. 4, p. 593-609, 2008.

HOESLI, Martin; GIACCOTTO, Carmelo; FAVARGER, Phillippe. Three new real estate price indexes for Geneva, Switzerland. Journal of Real Estate Finance and Economics, v. 15, n. 1, p. 93-109, 1997.

KENNEDY, Peter. Estimation with correctly interpreted dummy variables in Semilogarithmic Equations. American Economic Review, v. 74, n. 1, p. 801, 1981.

MAURER, Raimond; PITZER, Martin; SEBASTIAN, Steffen. Hedonic price indices for the Paris housing market. Allgemeines Statistisches Archiv, v. 88, p. 303-326, 2004.

McMILLEN, Daniel. Changes in the distribution of house prices over time: structural characteristics, neighborhood or coefficients? Journal of Urban Economics, v. 64, n. 3, p. 573 $598,2008$. 
NADALIN, Vanessa Gapriotti; FURTADO, Bernardo Alves. Índices de preços para imóveis: uma revisão. Boletim Regional, Urbano e Ambiental, n. 6, p. 21-32, 2011.

PAIXÃO, Luiz Andrés Ribeiro. Índice de preços hedônicos para imóveis: uma análise para o município de Belo Horizonte. Economia Aplicada, v. 19, n. 1, p. 5-29, 2015.

PAVESE, Piermassimo. Hedonic housing price indices: the turinese experience. Revista di Politica Economica, v. 95, n. 6, p. 113-148, 2007.

RÊGO, Paulo Augusto. Dinâmica dos aluguéis residenciais urbano entre 1995 e 2007 no Brasil: construção de índice e identificação dos fatores de influências. Dissertação (Mestrado em Ciências Econômicas)-Faculdade de Economia, Administração, Contabilidade e Ciência da Informação e Documentação, Universidade de Brasília, 2009.

ROSEN, Sherwin. Hedonic price and implicit markets: product differentiation in pure competition. Journal of Political Economy, v. 82, n. 1, p. 35-55, 1974.

ROZENBAUM, Sérgio. IMPA - Índice Municipal de Preços de Apartamentos: proposta e metodologia. Tese (Doutorado em Administração de Empresas)-Programa de Pós-Graduação em Administração de Empresas. Pontifícia Universidade Católica do Rio de Janeiro, 2009.

SANTOS, Flávia Vinhaes; SALAZAR, Marlon Bruno. Índice de Preços Imobiliários para o Brasil: estudos para discussão. Rio de Janeiro: Instituto Brasileiro de Geografia e Estatística (IBGE), 2011.

TRIPLETT, Jack. Handbook on hedonic and quality adjustments in price indexes: special application to information technology products. Paris: Organization for Economic Cooperation and Development (OECD), 2004. (Working Paper, 2004/9).

WALTL, Sofie R. Variation across price segments and locations: a comprehensive quantile regression analysis of the Sidney housing market. University of Graz, 2015. (Graz Economics Papers, 2015-09).

WAUGH, Frederik. Quality factors influencing vegetable prices. Journal of Farm Economics, v. 10, n. 2, p. 185-196, 1928. 